\title{
Helminth species richness in wild wood mice, Apodemus sylvaticus, is enhanced by the presence of the intestinal nematode Heligmosomoides polygyrus
}

\author{
J. M. BEHNKE ${ }^{1 *}$, C. EIRA ${ }^{2} \dagger$, M. ROGAN 3 , F. S. GILBERT ${ }^{1}$, J. TORRES ${ }^{4}$, J. MIQUEL $^{4}$ \\ and $\mathrm{J}$. W. LEWIS ${ }^{5}$ \\ ${ }^{1}$ School of Biology, University of Nottingham, University Park, Nottingham NG7 2RD, UK \\ ${ }^{2}$ CESAM and Department of Biology, University of Aveiro, Campus de Santiago 3810-193 Aveiro, Portugal \\ ${ }^{3}$ Department of Biological Sciences, University of Salford, Salford M5 4WT, UK \\ ${ }^{4}$ Laboratori de Parasitologia, Departament de Microbiologia i Parasitologia Sanitàries, Facultat de Farmàcia, \\ Universitat de Barcelona, Av Foan XXIII, sn, 08028 Barcelona, Spain \\ ${ }^{5}$ School of Biological Sciences, Royal Holloway University of London, Egham, Surrey TW20 0EX, UK
}

(Received 9 February 2009; revised 4 March 2009; accepted 5 March 2009)

\section{S UMMAR Y}

We analysed 3 independently collected datasets of fully censused helminth burdens in wood mice, Apodemus sylvaticus, testing the a priori hypothesis of Behnke et al. (2005) that the presence of the intestinal nematode Heligmosomoides polygyrus predisposes wood mice to carrying other species of helminths. In Portugal, mice carrying H. polygyrus showed a higher prevalence of other helminths but the magnitude of the effect was seasonal. In Egham, mice with H. polygyrus showed a higher prevalence of other helminth species, not confounded by other factors. In Malham Tarn, mice carrying H. polygyrus were more likely to be infected with other species, but only among older mice. Allowing for other factors, heavy residual $H$. polygyrus infections carried more species of other helminths in both the Portugal and Egham data; species richness in Malham was too low to conduct a similar analysis, but as $H$. polygyrus worm burdens increased, so the prevalence of other helminths also increased. Our results support those of Behnke et al. (2005), providing firm evidence that at the level of species richness a highly predictable element of co-infections in wood mice has now been defined: infection with $H$. polygyrus has detectable consequences for the susceptibility of wood mice to other intestinal helminth species.

Key words: Apodemus sylvaticus, associations of helminths, co-occurrence of helminths, Heligmosomoides polygyrus, helminths, helminth species richness, interactions between helminths.

\section{INTRODUCTION}

Interactions between different species of animals, or functional guilds of animals with shared or very similar niches, are the cornerstone of community ecology (Pedersen and Fenton, 2006; Suttle et al. 2007; Graham, 2008), and indeed it has been argued that such interactions define communities, contrasting them with assemblages of animals where the presence or absence of species is considered to be a purely random event (Janovy, 2002).

Most species of free-living hosts are subject to infection by a range of parasitic organisms and in nature, it is rare to encounter completely uninfected

* Corresponding author: School of Biology, University of Nottingham, University Park, Nottingham NG7 2RD, UK. Tel: 0115951 3208. Fax 0115951 3251. E-mail: jerzy.behnke@nottingham.ac.uk

$\dagger$ Current address: Sociedade Portuguesa de Vida Selvagem, Estação de Campo de Quiaios, Apartado 16-EC Quiaios, 3081-101 (Quiaios) Figueira da Foz, Portugal. hosts. Indeed most wild animals, and also humans, particularly those living in impoverished communities in developing regions of the world (Keusch and Migasena, 1982), harbour several species of parasites concurrently, 'polyparasitism' in the medical literature (Buck et al. 1978a,b). Whether multiple species infections actually constitute communities of helminths within hosts, so called infracommunities, has been a subject of debate for several decades. In some hosts, notably birds that harbour species-rich helminth communities, the evidence is indisputable, but in others such as fish and wild rodents characterized by relatively depauperate helminth communities, evidence in support of a role for interactions in structuring communities has been elusive (reviewed Behnke et al. 2001). This contrasts markedly with laboratory studies where interactions between helminths have been clearly demonstrated and mostly assigned to interactions mediated through the immune response of the host (Behnke et al. 2001; Behnke, 2008). The search for evidence of interactions among wild-caught hosts, has been hampered 
by a number of difficulties; for example, the statistical analyses required to dissect out the evidence for interactions is complex (Haukisalmi and Henttonen, 1998; Howard et al. 2001; Bottomley et al. 2005), and there is a lack of support for any specific interaction between particular parasites being a consistent enough feature wherever both species of parasites co-occur with the host. In contrast, a good example of a positive relationship that has been recorded many times in the medical literature, is that between the human intestinal nematodes Trichuris trichiura and Ascaris lumbricoides which not only cooccur but also show a positive quantitative relationship wherever the two species are endemic in human communities (Holland et al. 1989; Booth and Bundy, 1992; Howard et al. 2002; Tchuem Tchuenté et al. 2003; Behnke, 2008).

In our earlier paper (Behnke et al. 2005) we demonstrated 2 marked interactions among helminths of wild wood mice in the UK in 3 ecologically contrasting habitats; the positive relationship (evident as both co-occurrence and as a positive quantitative relationship) between Heligmosomoides polygyrus and the tapeworm Catenotaenia pusilla; and the positive relationship between $H$. polygyrus and species richness of other helminths. Both relationships are consistent with the idea that the long-lived $H$. polygyrus (Gregory et al. 1990), like its close relative H. bakeri (which, being a parasite of house mice, Mus musculus, has been explored extensively in laboratory work; Behnke, 1987; Behnke et al. 1992; Monroy and Enriquez, 1992), is aided in its survival strategy in wood mice by suppressing its host's capacity to mount protective immune responses in the intestine, and consequently provides an opportunity for other species to benefit from the altered host environment and to establish in and survive for longer than they otherwise might (reviewed by Behnke et al. 2001).

Whilst evidence of interactions between helminths in wild systems is not rare in the parasitological/ecological literature (Kisielewska, 1970; Montgomery and Montgomery, 1990; Haukisalmi and Henttonen, 1993), to date no relationship has stood the test of reexamination and been substantiated in other ecosystems where both the same host and parasite exist. In this paper, building on our initial report that the presence of $H$. polygyrus increases the likelihood that wood mice will harbour other species of helminths, we explore 2 entirely new datasets together with an extended dataset already partially analysed, with the specific aim of testing the robustness of our earlier findings. The first concerns helminths in wood mice from Portugal collected over a single calendar year, but from 6 ecologically contrasting habitats across all 4 seasons; the other 2 are from uniform habitats collected at the same time of the year (late summer) for 9 (Egham) and 16 (Malham) years. The extrinsic factors (e.g. year, season, site) known to influence helminth burdens differed between these 3 datasets, as did helminth species richness. Hence, if the relationship between $H$. polygyrus and the species richness of other helminth species can be demonstrated in these 3 independently collected datasets, then for the first time we will have demonstrated a robust element of the infracommunity structure of the helminths of A. sylvaticus in Europe.

\section{MATERIALS AND METHODS}

\section{Datasets}

The first dataset is derived from wood mice trapped in a coastal sand dune region (Dunas de Mira) in Portugal and localities in close proximity. In this 'Portuguese' dataset, wood mice were caught in 6 ecologically distinct sites represented by sand dunes, dune meadows, coastal pinewoods, pinewoods burned in 1993, lake margins and agricultural fields. The mice analysed were caught between autumn 2004 and the summer of 2005, structured into 4 seasons corresponding to autumn, winter, spring and summer in the region. For full details of the ecology of each of the sites and the methods used for trapping and necropsy of animals, see Eira et al. (2006), where the methods used in the field and in the laboratory are comprehensively detailed. The range of helminth species identified in these mice and the number of factors recorded, together with the levels of each factor, are summarized in Table 1.

The second dataset is derived from wood mice trapped in the grounds of the Royal Holloway, University of London, at Egham in Surrey. This 'Egham' dataset is based on mice trapped only during late summer, so it is not affected by seasonal variation. We (Behnke et al. 1999) analysed the epidemiology of helminths in mice caught in the period 1994 to 1997 and data from these 4 years were also utilized in our earlier analysis of interactions between helminths (Behnke et al. 2005), although that paper was largely based on another study originally conducted by Abu-Madi et al. $(1998,2000)$ and the data from Egham played only a minor role. The current analysis is based on the addition of a further 5 years of data to the Egham dataset, now spanning the period from 1994 to 2002. The range of helminth species identified in these mice and the number of factors recorded, together with the levels of each factor, are summarized in Table 1.

The third dataset concerns wood mice trapped in the woodlands north of Malham Tarn in Yorkshire, UK. This 'Malham' dataset is based also on mice trapped only during late summer, but across a 16-year period from 1993 to 2008. The range of helminth species identified in these mice and the number of factors recorded, together with the levels of each factor, are summarized in Table 1. Details of the methods used to catch, necropsy mice and allocate them into age classes can be found in Rogan et al. (2007). 
Table 1. Prevalence of helminths from the Portuguese, Egham and Malham sites

\begin{tabular}{|c|c|c|c|c|c|c|c|c|c|}
\hline \multirow[b]{3}{*}{ Species } & \multicolumn{3}{|c|}{ Portugal* } & \multicolumn{3}{|c|}{ Egham $\dagger$} & \multicolumn{3}{|c|}{ Malham§ } \\
\hline & \multirow{2}{*}{$\begin{array}{l}\text { Preva- } \\
\text { lence } \\
(\%)\end{array}$} & \multicolumn{2}{|c|}{ Confidence limit } & \multirow{2}{*}{$\begin{array}{l}\text { Preva- } \\
\text { lence } \\
(\%)\end{array}$} & \multicolumn{2}{|c|}{ Confidence limit } & \multirow{2}{*}{$\begin{array}{l}\text { Preva- } \\
\text { lence } \\
(\%)\end{array}$} & \multicolumn{2}{|c|}{ Confidence limit } \\
\hline & & Lower & Upper & & Lower & Upper & & Lower & Upper \\
\hline \multicolumn{10}{|l|}{ Nematodes } \\
\hline Heligmosomoides polygyrus & $54 \cdot 9$ & $48 \cdot 3$ & $61 \cdot 2$ & $77 \cdot 7$ & $73 \cdot 5$ & $81 \cdot 4$ & $73 \cdot 0$ & $68 \cdot 5$ & $77 \cdot 4$ \\
\hline Syphacia stroma & $30 \cdot 7$ & $25 \cdot 1$ & $36 \cdot 9$ & $50 \cdot 6$ & $46 \cdot 0$ & $55 \cdot 3$ & $6 \cdot 1$ & $3 \cdot 8$ & $9 \cdot 2$ \\
\hline Syphacia frederici & $24 \cdot 4$ & $19 \cdot 2$ & $30 \cdot 4$ & 0 & - & & 0 & - & \\
\hline Rictularia proni & $7 \cdot 0$ & $4 \cdot 3$ & $11 \cdot 1$ & 0 & - & & 0 & - & \\
\hline Trichuris muris & $0 \cdot 2$ & 0 & $2 \cdot 6$ & $14 \cdot 2$ & $11 \cdot 1$ & $17 \cdot 8$ & $0 \cdot 3$ & 0 & $2 \cdot 1$ \\
\hline Gongylonema neoplasticum & $1 \cdot 1$ & 0 & 4 & 0 & - & & 0 & - & \\
\hline Aspiculuris tetraptera & $0 \cdot 2$ & 0 & $2 \cdot 6$ & $1 \cdot 7$ & $0 \cdot 7$ & $3 \cdot 5$ & 0 & - & \\
\hline Angiostrongylus dujardini & $28 \cdot 2$ & $22 \cdot 6$ & $34 \cdot 5$ & 0 & - & & 0 & - & \\
\hline Aoncotheca murissylvatici & 0 & - & & $6 \cdot 0$ & $3 \cdot 9$ & $8 \cdot 8$ & $6 \cdot 4$ & $4 \cdot 1$ & $9 \cdot 6$ \\
\hline Pelodera strongyloides & 0 & - & & $21 \cdot 5$ & $17 \cdot 8$ & $25 \cdot 6$ & - & - & \\
\hline \multicolumn{10}{|l|}{ Adult cestodes } \\
\hline Rodentolepis straminea & $1 \cdot 8$ & $0 \cdot 6$ & $4 \cdot 7$ & 0 & - & & 0 & - & \\
\hline Skrajbinotaenia lobata & $3 \cdot 2$ & $1 \cdot 2$ & $6 \cdot 5$ & 0 & - & & 0 & - & \\
\hline Microsomacanthus crenata & 0 & - & & $28 \cdot 3$ & $24 \cdot 2$ & $32 \cdot 8$ & 0 & - & \\
\hline \multicolumn{10}{|l|}{ Larval cestodes } \\
\hline Cladotaenia globifera & $0 \cdot 2$ & 0 & $2 \cdot 6$ & 0 & - & & $1 \cdot 0$ & 0 & $3 \cdot 1$ \\
\hline Taenia parva & $14 \cdot 9$ & $10 \cdot 8$ & $20 \cdot 1$ & 0 & - & & 0 & - & \\
\hline Taenia taeniaformis & 0 & - & & $4 \cdot 3$ & $2 \cdot 6$ & $6 \cdot 7$ & $0 \cdot 7$ & 0 & $2 \cdot 4$ \\
\hline \multicolumn{10}{|l|}{ Trematoda } \\
\hline Brachylaemus recurvum & 0 & - & & $1 \cdot 7$ & $0 \cdot 7$ & $3 \cdot 5$ & $1 \cdot 4$ & $0 \cdot 3$ & $3 \cdot 5$ \\
\hline Corrigia vitta & 0 & - & & $19 \cdot 3$ & $15 \cdot 8$ & $23 \cdot 4$ & 0 & - & \\
\hline Plagiorchis muris & 0 & - & & 0 & - & & $17 \cdot 6$ & $13 \cdot 8$ & $22 \cdot 0$ \\
\hline Factors measured & No. of & levels & & No. of & levels & & No. of 1 & evels & \\
\hline \multicolumn{10}{|l|}{ Extrinsic } \\
\hline Site & 6 & & & 1 & & & 1 & & \\
\hline Year & 1 & & & 9 & & & 16 & & \\
\hline Season & 4 & & & 1 & & & 1 & & \\
\hline \multicolumn{10}{|l|}{ Intrinsic } \\
\hline Age & 3 & & & 3 & & & 3 & & \\
\hline Sex & 2 & & & 2 & & & 2 & & \\
\hline \multicolumn{10}{|l|}{ Hosts } \\
\hline Males & 235 & & & 153 & & & 179 & & \\
\hline Females & 208 & & & 80 & & & 117 & & \\
\hline Combined & 443 & & & 233 & & & 296 & & \\
\hline
\end{tabular}

* Eira et al. (2006).

$\dagger$ For the first 4 years (1994-1997) see Behnke et al. (1999). Data from 1998 to 2002 are in preparation for submission.

$\S$ The full analysis of this dataset has not been published.

\section{Hypotheses}

In contrast to our earlier paper where we looked for evidence of interactions between species employing a range of different analytical procedures, in this paper we set out specifically to test the a priori hypothesis that mice infected with $H$. polygyrus would be predisposed to infection with other helminths, and should therefore show a higher prevalence and a higher species richness of other helminths. We used 2 response variables. Firstly, each animal was recorded as either infected or not infected with any of the other species of helminths (i.e. excluding $H$. polygyrus). This binary factor is referred to hereafter as 'presence/absence of other helminth species'. Secondly we recorded the number of other helminth species in each animal; this factor is referred to as 'species richness of other helminths'.

\section{Statistical analysis}

Binary prevalence data were analysed by maximum likelihood techniques based on log-linear analysis of contingency tables, using the software package SPSS (Version 12.0.1.). Full factorial models incorporated the intrinsic factors age ( 3 age classes, all data-sets) and sex (2 levels, males and females), and the extrinsic factors of site (6 levels, Portuguese dataset), year of survey (9 levels [1994 to 2002] in the Egham 
data-set or 16 [1993 to 2008] in the Malham dataset) and season (4 levels, corresponding to 4 seasons in the Portuguese data-set). Infection with $H$. polygyrus was considered as a binary factor (present/absent), as was also the presence/absence of other helminth species. One of the species of helminths recorded in Portugal, Angiostrongylus dujardini does not inhabit the intestine or peritoneal cavity of the host, and in a final phase of this analysis we also examined the effect of the presence/absence of $H$. polygyrus on other helminth species but this time excluding $A$. dujardini. At Egham Pelodera strongyloides was recorded, another species that does not inhabit the intestine, and the same approach was used here.

In each case, beginning with the most complex model, involving all possible main effects and interactions, elements that did not contribute significantly to explaining variation in the data were eliminated in a stepwise fashion, beginning with the highest-level interaction. A minimum-sufficient model was then obtained, for which the likelihood ratio (L.R.) of $\chi^{2}$ was not significant, indicating that the model was sufficient in explaining the data. The importance of each term in the final model was assessed by the probability that its exclusion would alter the model significantly: these values are given in the text, but only for those terms that included both the presence/ absence of $H$. polygyrus and the presence/absence of other helminth species. The number of other terms is also stated, but for brevity we do not give the details of each (these can be obtained from J.M.B. by request). Prevalence data (percentage of animals infected with various combinations) are shown with $95 \%$ confidence limits $\left(\mathrm{CL}_{95}\right)$, calculated with bespoke software following Rohlf and Sokal (1995).

Analysis of quantitative data was conducted in 2 phases. Firstly we fitted generalized linear models (GLM) with negative binomial errors, normal errors on Box-Cox transformed data, Poisson errors or quasibinomial errors, as relevant, using $\mathrm{R}$ version 2.2.1 (R Core Development Team). Models were fitted using the appropriate GLM routine in the MASS library of R (Venables and Ripley, 1997). We first fitted full factorial models and if these converged, we employed the STEP procedure in R to simplify the models. We then tested the significance of the highest-order interaction by comparing models with or without that interaction. Next, the significance of each 3-way interaction was tested by comparing models with and without that interaction, but incorporating all the other 3-way interactions, 2 -way interactions and main effects. This was repeated for 2-way interactions and then main effects. Minimum-sufficient models were then fitted (all significant interactions and main effects + any nonsignificant main effects that featured in interactions) and the process was repeated to obtain values for changes in deviance, test statistics and probabilities. The residuals of these models were saved.
Secondly, following Lotz and Font (1994) and Behnke et al. (2005), we confined further analysis to animals that harboured $H$. polygyrus and at least 1 worm of another species. This approach avoids false conclusions generated by excessive zero values in correlational tests. We assessed the correlation (Pearson's coefficient of correlation) between the residuals of the minimum-sufficient GLM of $H$. polygyrus and the residuals of GLM of species richness of other helminths. For these we used onetailed tests, since we were testing a priori hypotheses with clearly predicted positive relationships. In the case of the final analysis of the Malham Tarn dataset, we confined the analysis to mice infected with $H$. polygyrus and calculated the prevalence of other species, for reasons given in the Results section.

\section{RESULTS}

\section{Prevalence of species}

The prevalence of species of helminths in all 3 studies is summarized in Table 1. Analysis of the factors influencing the prevalence and abundance of helminths in the Portuguese dataset has been published (Eira et al. 2006). Behnke et al. (1999) provided the analysis of prevalence and abundance of helminths in the period 1994-1997 from Egham, but the analysis of the full dataset to 2002 is still in preparation. Only the data on Plagiorchis muris in the period 1993-2005 have been published for the Malham dataset (Rogan et al. 2007).

The Portuguese dataset was the most species-rich with 12 species of helminths recovered, 5 of which showed prevalence exceeding $10 \%$. The prevalence of $H$. polygyrus was $54.9 \%$, and the second most common species was Syphacia stroma. One of the listed species, A. dujardini was not associated with the intestine, but rather with the blood vessels connecting the lungs with the heart.

The dataset from Egham was based on fewer animals, and 10 species of helminths were identified. $H$. polygyrus was again the most common showing a higher prevalence than in the Portuguese dataset $(77 \cdot 7 \%)$. S. stroma was again the second mostcommon species. Six species showed prevalence exceeding $10 \%$. One species, P. strongyloides, was not associated with the intestine, but rather with the skin, nasal passages and the eye sockets (Hominick and Aston, 1981).

Wood mice from Malham were infected with 8 species of helminths and, as elsewhere, $H$. polygyrus was the most common $(73 \cdot 0 \%)$. Here, S. stroma was rarer than in the first 2 datasets $(6 \cdot 1 \%)$ and instead the second most-common species encountered was the digenean $P$. muris $(17 \cdot 6 \%)$. H. polygyrus and $P$. muris were the only 2 species to occur in more than $10 \%$ of the animals. $P$. strongyloides was present in the population, but infections with this species were 
only quantified in some years, and therefore the species was excluded from the analysis.

Only 1 species of nematode was common $(H$. polygyrus) but 3 others (S. stroma, Trichuris muris and Aspiculuris tetraptera), were present in all 3 studies. The last of these was recorded in 1 mouse from Malham but the identity was not confirmed and it was removed from the analysis. S. stroma was common in the Portuguese and Egham datasets but far less so in the Malham wood mice. T. muris was more common in the Egham dataset than in the Portuguese or Malham datasets. None of the adult cestodes overlapped among these studies, but larval T. taeniaeformis was encountered in both Egham and Malham datasets.

\section{Multiple species infections}

The species density distributions are illustrated in Fig. 1 (Janovy et al. 1995). In the first 2 datasets (Portuguese and Egham) the maximum number of helminth species harboured was 6 , whereas at Malham no mice harboured more than 3 species concurrently. In the Portuguese dataset (Fig. 1A), 31·4\% $(25 \cdot 5-37 \cdot 8)$ were infected with just a single species of helminth, but $50 \cdot 8 \%(44 \cdot 3-57 \cdot 3)$ harboured more than a single species. At Malham (Fig. 1C) most wood mice harboured just 1 species, $(53 \cdot 4 \%$, 48.158.6) and the percentage harbouring more than 1 species concurrently was correspondingly lower $(25 \cdot 3 \%, 21 \cdot 0-30 \cdot 2)$. In the Egham dataset (Fig. 1B) $17 \cdot 2 \%(13 \cdot 8-21 \cdot 1)$ of mice were infected with 1 species and $72 \cdot 5 \%(68 \cdot 2-76 \cdot 5)$ harboured more than just 1 species.

Effect of Heligmosomoides polygyrus on prevalence of other helminths

Portuguese sites. In this dataset 52.5\% (46.0-60.0) of mice without $H$. polygyrus were infected with other helminths, but the prevalence was almost $8 \%$ higher among mice with $H$. polygyrus $(60.5 \%$, $55 \cdot 7-65 \cdot 0)$. There was no significant difference between the sexes in this respect (otherwise sex would have been retained as a factor in the minimum sufficient model; see below) and not surprisingly the difference was evident in summary data in both males (57.0\% of mice without $H$. polygyrus versus $67 \cdot 4 \%$ of mice with $H$. polygyrus) and in females $(48 \cdot 0 \%$ versus $51.9 \%$, respectively), with the discrepancy greater, but not significantly so among male mice (10.4\% vs $3.9 \%$ ).

Log-linear analysis revealed just 1 relevant significant interaction term (season $*$ presence/absence of $H$. polygyrus $*$ presence/absence of other helminth species: L.R. $\left.\chi^{2}{ }_{3}=9 \cdot 43, P=0 \cdot 024\right)$ in the minimumsufficient model (goodness of fit of model L.R. $\chi^{2}{ }_{114}=$ $111 \cdot 55, P=0 \cdot 55$; note that this was a model in which
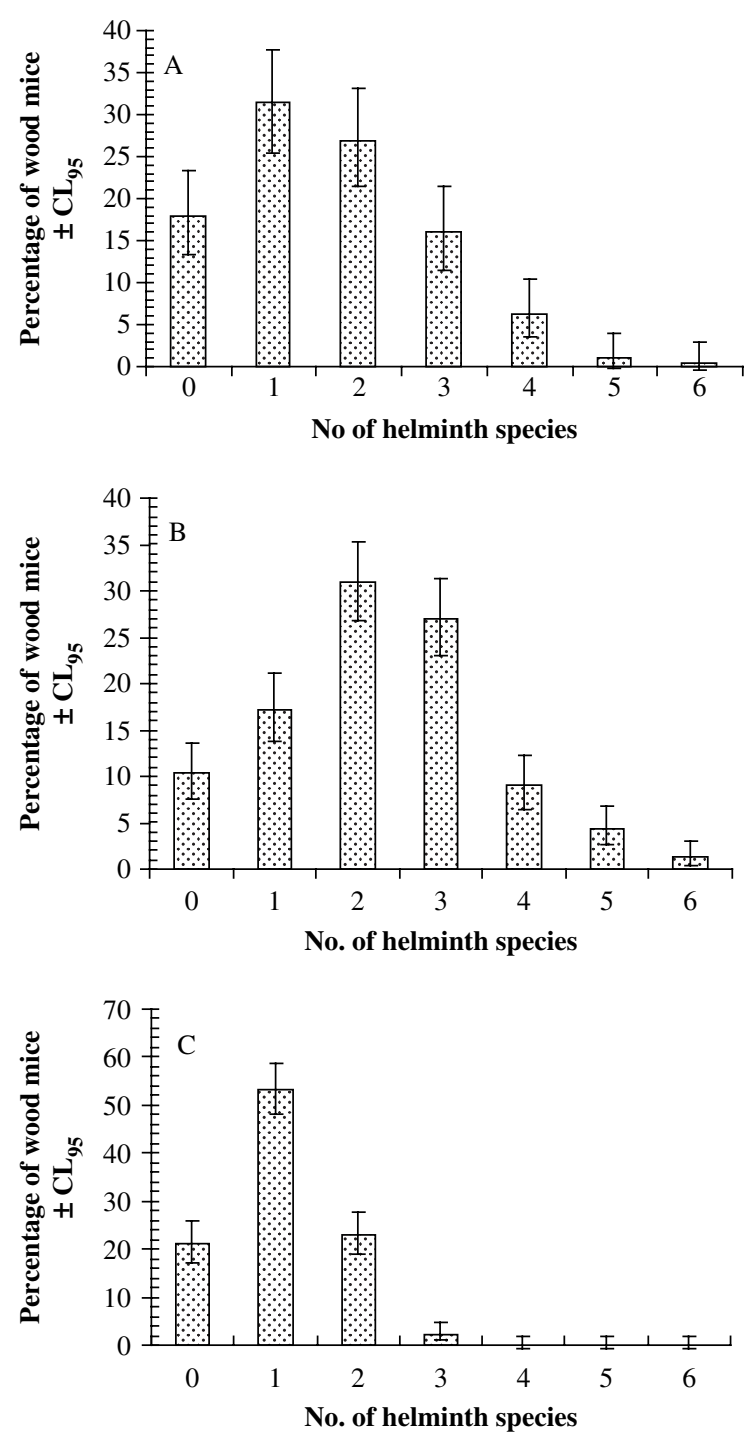

Fig. 1. Species density distributions for the Portuguese (A), Egham (B) and Malham (C) datasets.

age was not fitted). This interaction is illustrated in Fig. 2A, where it can be seen that in each of the 4 seasons, mice carrying $H$. polygyrus also showed a higher prevalence of other species of helminths.

Exclusion of $A$. dujardini (because it is not an intestinal species) from the category 'other helminth species' yielded a more complex model with an interaction between site, season and presence/absence of $H$. polygyrus (L.R. $\chi_{15}^{2}=30 \cdot 26, P=0 \cdot 011$ ), but it was not possible to probe this further because with 48 possible combinations (season $=4$, site $=6$, presence/ absence of $H$. polygyrus $=2$, therefore $4 \times 6 \times 2=48$ ) some cells had no data and others were based on very small sample sizes. However, examining the relationship with just season (excluding site) gave much the same outcome as earlier, with mice infected with $H$. polygyrus generally showing higher prevalence of other helminth species (excluding $A$.dujardini) in all months except the winter (prevalence of other helminths was $69 \cdot 2 \%$ vs $56 \cdot 3 \%$ in spring, $57 \cdot 1 \%$ vs $42 \cdot 2 \%$ in the summer, $67 \cdot 5 \%$ vs $59 \cdot 0 \%$ in the autumn for 

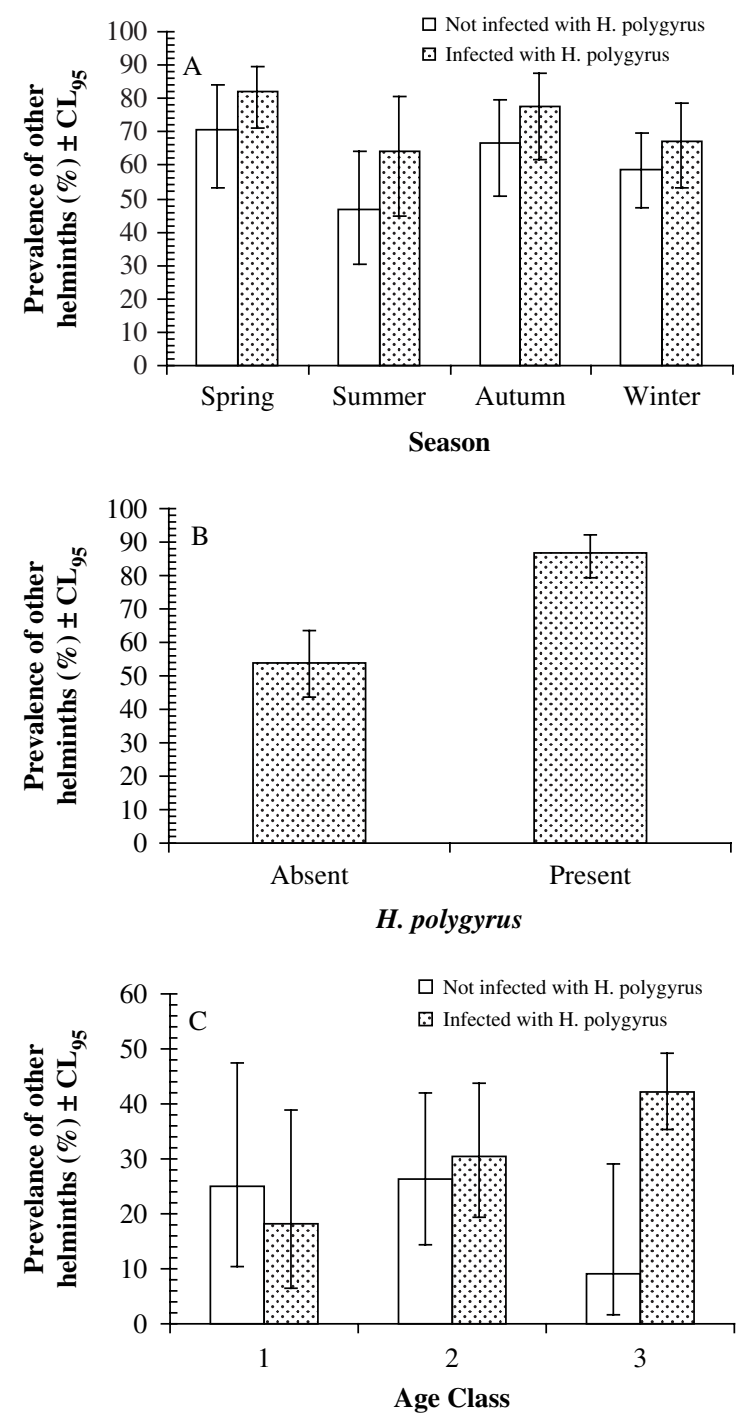

Fig. 2. Prevalence of other species of helminths in wood mice with or without Heligmosomoides polygyrus. (A) Interaction with season in the Portuguese dataset. The sample sizes were 48, 45, 39 and 68 for mice without H. polygyrus, and 78, 28, 40 and 97 for those with $H$. polygyrus in spring, summer, autumn and winter, respectively. (B) Unaffected by other factors in wood mice at Egham. The sample sizes were 52 for mice without $H$. polygyrus and 181 for those with $H$.polygyrus. (C) Interaction with age in the Malham dataset. The sample sizes were 20,38 and 22 for mice without $H$. polygyrus, and 22, 92 and 102 for those with $H$. polygyrus in age classes 1, 2 and 3 respectively. For statistical analysis see text.

mice with and without $H$. polygyrus respectively: in the winter, prevalence was almost identical at $51 \cdot 5 \%$ in mice with $H$. polygyrus compared with $52.9 \%$ in those without $H$. polygyrus).

Egham site. The Egham dataset showed a larger divergence in prevalence with other helminth species between wood mice infected $(86 \cdot 7 \%, 79 \cdot 3-92 \cdot 1)$ and not infected $(53.9 \%, 43 \cdot 7-63 \cdot 5)$ with $H$. polygyrus (Fig. 2B). Analysis by log-linear procedures generated a minimum-sufficient model with 4 terms (L.R. $\left.\chi^{2}{ }_{125}=82 \cdot 36, P=0 \cdot 99\right)$, one of which was presence/absence of $H$. polygyrus $*$ presence/absence of other helminth species: this was highly significant and not confounded by other factors (L.R. $\chi^{2}{ }_{1}=23 \cdot 7$, $P<0 \cdot 0001)$.

The difference in prevalence was also clearly apparent in both sexes. In male wood mice not infected with $H$. polygyrus the prevalence of other helminth species was $55 \cdot 3 \%(39 \cdot 4-69 \cdot 9)$ compared to $88 \cdot 7 \%$ (83.1-92.7) among those with $H$. polygyrus. In females the values were very similar $(50 \cdot 0 \%[23 \cdot 8-76 \cdot 2]$ versus $83 \cdot 3 \%[73 \cdot 5-90 \cdot 2])$.

Here again, 1 species was not intestinal. P. strongyloides has a phoretic relationship with mice, exploiting them only for temporary refuge when environmental conditions are detrimental to survival (Hominick and Aston, 1981). It occurs in the lachrymal ducts, eye sockets and skin during its residence in mice, before emerging and completing its life cycle externally when the mice have died. Therefore, we repeated the analysis excluding $P$. strongyloides from the category 'other helminth species'. The outcome was much the same as earlier. The mostparsimonious model (L.R. $\chi_{151}^{2}=125 \cdot 8, P=0.933$ ), included 4 terms, of which 1 was presence/absence of $H$. polygyrus* presence/absence other helminth species (excluding $P$. strongyloides), not confounded by other factors, and an essential component of the final model (L.R. $\chi^{2}{ }_{1}=22 \cdot 95, P<0 \cdot 0001$ ).

Malham Tarn site. As in the other datasets, prevalence of other helminths was higher among mice carrying $H$. polygyrus $(34.7 \%, 30.49-39 \cdot 16)$ compared with those without $H$. polygyrus $(21 \cdot 3 \%$, $12 \cdot 62-33 \cdot 35)$, and this difference was evident in both males $(34 \cdot 5 \%$ [26.95-42.75] versus $24 \cdot 3 \%$ [12.83$39 \cdot 76])$ and females $(35 \cdot 1 \%$ [24.58-47.05] versus $18 \cdot 6 \%[8 \cdot 38-35 \cdot 09])$.

Log-linear analysis generated a minimumsufficient model (L.R. $\left.\chi^{2}{ }_{350}=269 \cdot 2, P=1 \cdot 0\right)$ with just 2 terms 1 of which was relevant (presence/absence of $H$. polygyrus $*$ presence/absence of other helminths $*$ age class; L.R. $\left.\chi^{2}{ }_{2}=7 \cdot 0, P=0 \cdot 029\right)$, indicating that the prevalence of other helminth species depended on both the prevalence of $H$. polygyrus and host age (Fig. 2C). Although there was no difference in prevalence of other helminths among wood mice in age classes 1 and 2, among the oldest mice (age class 3 ) prevalence of other helminths was more than 4-fold higher in mice with, compared to those without, H. polygyrus.

Effect of Heligmosomoides polygyrus on species richness of other helminths

Abundance of infections and species richness. The mean abundance of each of the species recovered from each study site is summarized in Table 2. This 
Table 2. Abundance of helminths from the Portuguese, Egham and Malham sites

(The table shows the pooled abundance across all subsets of data.)

\begin{tabular}{|c|c|c|c|c|c|c|}
\hline \multirow[b]{2}{*}{ Species } & \multicolumn{2}{|l|}{ Portugal } & \multicolumn{2}{|l|}{ Egham } & \multicolumn{2}{|l|}{ Malham } \\
\hline & Mean \pm & S.E.M. & Mean \pm & S.E.M. & Mean \pm & S.E.M. \\
\hline \multicolumn{7}{|l|}{ Nematodes } \\
\hline Heligmosomoides polygyrus & $15 \cdot 7$ & $2 \cdot 40$ & $11 \cdot 4$ & $1 \cdot 13$ & $14 \cdot 4$ & $1 \cdot 63$ \\
\hline Syphacia stroma & $16 \cdot 7$ & $2 \cdot 65$ & $23 \cdot 6$ & $5 \cdot 53$ & $0 \cdot 8$ & $0 \cdot 39$ \\
\hline Syphacia frederici & $6 \cdot 7$ & $1 \cdot 40$ & 0 & - & 0 & - \\
\hline Rictularia proni & $0 \cdot 18$ & $0 \cdot 038$ & 0 & - & 0 & - \\
\hline Trichuris muris & $0 \cdot 002$ & $0 \cdot 002$ & $0 \cdot 55$ & $0 \cdot 126$ & $0 \cdot 05$ & $0 \cdot 054$ \\
\hline Gongylonema neoplasticum & $0 \cdot 02$ & $0 \cdot 013$ & 0 & - & 0 & - \\
\hline Aspiculuris tetraptera & $0 \cdot 05$ & $0 \cdot 05$ & $0 \cdot 011$ & $0 \cdot 011$ & 0 & - \\
\hline Angiostrongylus dujardini & $1 \cdot 1$ & $0 \cdot 18$ & 0 & - & 0 & - \\
\hline Aoncotheca murissylvatici & 0 & - & $0 \cdot 23$ & $0 \cdot 095$ & $0 \cdot 4$ & $0 \cdot 19$ \\
\hline Pelodera spp. & 0 & - & $1 \cdot 7$ & $0 \cdot 65$ & 0 & - \\
\hline \multicolumn{7}{|l|}{ Adult cestodes } \\
\hline Rodentolepis straminea & $0 \cdot 32$ & $0 \cdot 270$ & 0 & - & 0 & - \\
\hline Skrajbinotaenia lobata & $0 \cdot 08$ & $0 \cdot 029$ & 0 & - & 0 & - \\
\hline Microsomacanthus crenata & 0 & - & $3 \cdot 7$ & $0 \cdot 92$ & 0 & - \\
\hline \multicolumn{7}{|l|}{ Larval cestodes } \\
\hline Cladotaenia globifera & $0 \cdot 002$ & $0 \cdot 002$ & 0 & - & $0 \cdot 01$ & $0 \cdot 006$ \\
\hline Taenia parva & $0 \cdot 22$ & $0 \cdot 032$ & 0 & - & 0 & - \\
\hline Taenia taeniaeformis & 0 & - & $0 \cdot 24$ & $0 \cdot 146$ & $0 \cdot 007$ & $0 \cdot 005$ \\
\hline \multicolumn{7}{|l|}{ Trematodes } \\
\hline Corrigia vitta & 0 & - & $1 \cdot 2$ & $0 \cdot 24$ & 0 & - \\
\hline Brachylaemus recurvum & 0 & - & $0 \cdot 047$ & $0 \cdot 035$ & $0 \cdot 13$ & $0 \cdot 12$ \\
\hline Plagiorchis muris & 0 & - & 0 & - & $2 \cdot 0$ & $0 \cdot 50$ \\
\hline
\end{tabular}

shows quite clearly the remarkably similar abundance of $H$. polygyrus in these 3 study sites, despite their geographical separation and climatic differences. It also shows the degree to which this species dominated the infracommunities of the wood mice. Only S. stroma showed comparable abundances in 2 of the study sites, and the other species were far less abundant.

Mean species richness was highest at Egham $(2 \cdot 25 \pm 0 \cdot 087)$, lower in Portugal $(1 \cdot 67 \pm 0 \cdot 058)$ and lowest at Malham $(1 \cdot 06 \pm 0 \cdot 043)$. When $H$. polygyrus was excluded these values became $1.48 \pm 0.074$, $1 \cdot 12 \pm 0 \cdot 050$ and $0 \cdot 33 \pm 0 \cdot 030$, respectively. Clearly at Malham very few animals were infected with helminths other than $H$. polygyrus $(31 \cdot 1 \%, 26 \cdot 34$ $36 \cdot 20)$, compared with $67 \cdot 5 \%(61 \cdot 11-73 \cdot 35)$ in the Portuguese dataset and $79 \cdot 4 \%(75 \cdot 35-82.91)$ in Egham.

Portuguese sites. The species richness of other helminths was analysed by a GLM model with Poisson errors, initially fitting all 4 factors (site, season, host age and sex) in a full factorial model. However, the data were best accounted for by a minimumsufficient model that comprised only the main effects of season $\left(\chi^{2}{ }_{3}=10 \cdot 3, P=0 \cdot 02\right)$, site $\left(\chi^{2}{ }_{5}=27 \cdot 1, P<\right.$ $0 \cdot 00001)$ and host age $\left(\chi_{2}^{2}=56 \cdot 1, P<0 \cdot 00001\right)$. The precise effect of each of these factors on species richness is described fully by Eira et al. (2006). The residuals from this analysis were saved.
Attempts to fit a model with negative binomial errors for the abundance of $H$. polygyrus failed to converge, so the data were Box-Cox transformed (BoxCox lambda $=-1 \cdot 018, \mathrm{Cl}_{95}=-1 \cdot 011$ and $-1 \cdot 027$; Likelihood $=-754 \cdot 635$ ) and analysed by a model with normal errors. The minimum-sufficient model was season $\left(F_{3,431}=15 \cdot 9, P<0 \cdot 00001\right)+\operatorname{site}\left(F_{5,431}=\right.$ $28 \cdot 9, \quad P<0 \cdot 00001)+$ sex $\quad(\mathrm{P}=\mathrm{NS})+$ age $\quad\left(F_{2,431}=\right.$ $15 \cdot 7, P<0 \cdot 00001)+$ season $*$ site $\left(F_{13,429}=4 \cdot 47, P<\right.$ $0 \cdot 00001)+$ age $* \operatorname{sex} \quad\left(F_{2,418}=3 \cdot 59, \quad P=0 \cdot 028\right) . \quad$ The residuals from this model were saved.

Finally the relationship between the $H$. polygyrus residuals and the species richness residuals was examined by correlation using data from mice with at least 1 individual of $H$. polygyrus and 1 worm of another species. These were significantly correlated ( $r_{\mathrm{p}}=0 \cdot 161$, one-tailed test, $n=178, P=0 \cdot 016$ ), and are illustrated as raw values in Fig. 3A and arranged in convenient range classes in Fig. $4 \mathrm{~A}$.

Egham site. The species richness of other helminths was analysed by a GLM model with Poisson errors, initially fitting all 3 factors (year, host age and sex). Only age played a significant role in explaining the species richness of other helminth species $\left(\chi_{2}^{2}=28 \cdot 4\right.$, $\left.P=6 \cdot 9 \times 10^{-7}\right)$ with the effect of year just outside significance $\left(\chi_{8}^{2}=14 \cdot 5, P=0 \cdot 069\right)$ : neither host sex nor any interactions were significant predictors. Accordingly, to err on the side of caution, we saved the residuals of the Poisson model with just host age and 

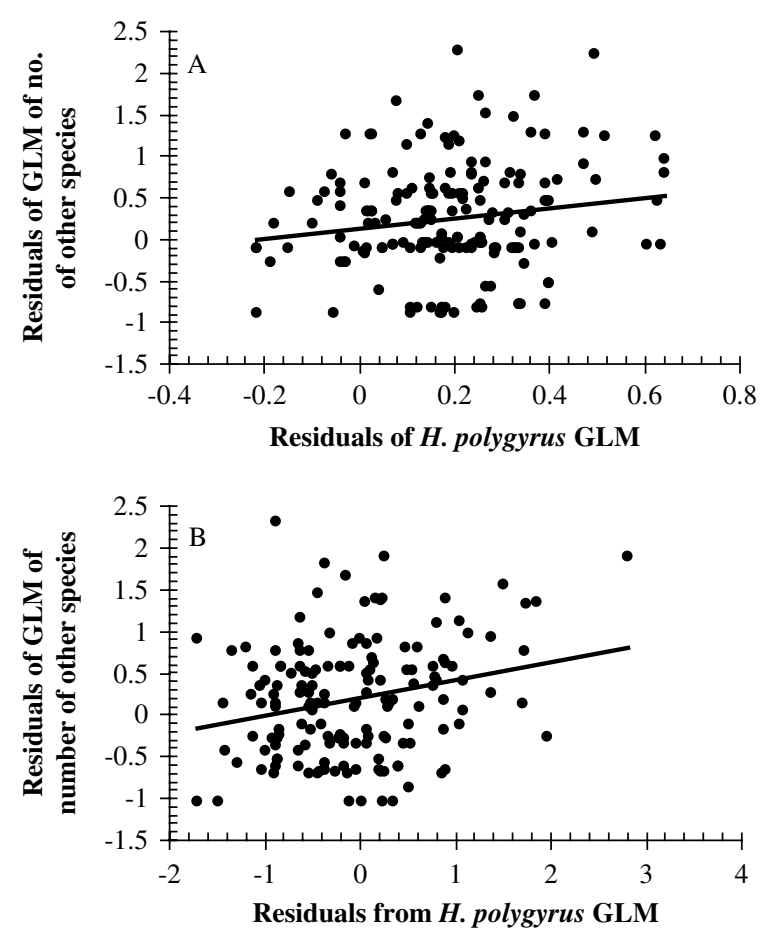

Fig. 3. Correlation between the intensity of Heligmosomoides polygyrus infection and number of other species of helminths harboured by wood mice. (A) The relationship in the Portuguese dataset between the residuals of a minimum-sufficient GLM of the species richness of other helminths (Poisson errors, with season, site and age as explanatory factors) and the residuals of a minimum-sufficient GLM of the abundance of $H$. polygyrus (Box-Cox transformed data and model with normal errors, and season, site, sex, age, season $*$ site and age $*$ sex as explanatory factors and interactions). (B) The relationship at Egham between the residuals of a minimum-sufficient GLM of the species richness of other helminths (Poisson errors with year and host age as explanatory factors) and the residuals of a minimum-sufficient GLM of the abundance of $H$. polygyrus (model with negative binomial errors and year and host age as explanatory factors). Both analyses were confined to mice which harboured at least 1

H. polygyrus and 1 worm of another species and the full statistical analysis is given in the text. Lines of best fit are provided to guide the eye, and these were fitted by a least squares routine in Microsoft Excel.

year as the explanatory factors, and preferentially conducted further analyses using this model.

Analysis of the abundance of $H$. polygyrus was carried out by GLM with negative binomial errors. The minimum-sufficient model was year $\left(\mathrm{LR} \chi^{2}{ }_{8}=\right.$ $26 \cdot 4, P=0 \cdot 00088)$ plus age $\left(\mathrm{LR} \chi^{2}{ }_{2}=39 \cdot 1, P=3 \cdot 3 \times\right.$ $\left.10^{-9}\right)$. The main effect of host sex and all possible interactions were not significant. The residuals of this model were saved.

The species-richness residuals and the $H$. polygyrus abundance residuals were then correlated using mice with at least 1 individual of $H$. polygyrus and 1 worm of another species. They were significantly correlated $\left(r_{p}=0 \cdot 24, n=157, P=0 \cdot 0015\right.$ one-tailed test) and are illustrated as raw values in Fig. $3 \mathrm{~B}$ and arranged in convenient range classes in Fig. 4B.

Additionally we also examined the relationship between $H$. polygyrus abundance residuals and the species-richness residuals of a model with just age as the explanatory factor. This gave a lower value for $r_{p}$ but still significant $\left(r_{p}=0 \cdot 191\right.$, one-tailed test, $n=$ 157, $P=0 \cdot 008)$.

Malham Tarn site. The Malham dataset could not be examined in exactly the same manner because species richness was low, and as explained earlier only $31 \cdot 1 \%$ of mice harboured helminths other than H. polygyrus. Moreover, the maximum number of other helminth species was 2 , and only 7 mice fell into this category. Therefore, we fitted a full factorial GLM model with negative binomial errors to the abundance of $H$. polygyrus. This model could not be simplified, comprising year $\left(\mathrm{LR} \chi_{15}^{2}=27 \cdot 3, P=\right.$ $0 \cdot 026)+$ age $\left(\mathrm{LR} \chi_{2}{ }_{2}=35 \cdot 2, P=2 \cdot 299 \times 10^{-8}\right)+$ year $*$ sex $\left(\mathrm{LR} \chi^{2}{ }_{15}=27 \cdot 8, P=0 \cdot 023\right)+$ year $*$ age $\left(\mathrm{LR} \chi^{2}{ }_{29}=\right.$ $62 \cdot 1, \quad P=0 \cdot 0003)+$ sex $*$ age $\quad\left(\mathrm{LR} \chi_{2}{ }_{2}=7 \cdot 2, \quad P=\right.$ $0 \cdot 028)+\operatorname{sex} *$ age $*$ year $\left(\mathrm{LR} \chi_{17}^{2}=28 \cdot 6, \quad P=0 \cdot 038\right)$. The main effect of sex was not significant but this was retained because sex featured in significant interactions. The residuals from this model were saved.

We then sorted the residuals of the $H$. polygyrus GLM into 3 convenient abundance classes, and for animals that were infected with $H$. polygyrus we calculated the prevalence of other helminth species in each of the 3 classes (Fig. 4C). These indicate that after controlling for age, sex and year and their interactions, the prevalence of other species increased as $H$. polygyrus abundance increased. In order to test the significance of this relationship, we fitted the fixed factors year, sex and age, and the residuals of $H$.polygyrus as a covariate in a GLM with quasibinomial errors, with the dependent variable being the binary presence/absence of other helminths species: the data were confined to mice infected with $H$. polygyrus. Full factorial models did not converge but fitting just the main effects simplified to a model with just age and $H$. polygyrus residuals (age, $\chi^{2}{ }_{2}=8 \cdot 1, P=0 \cdot 018$; $H$. polygyrus residuals, $\left.\chi^{2}{ }_{1}=9 \cdot 8, P=0 \cdot 002\right)$.

In Fig. 4D we have reproduced the results of our earlier published analysis (Behnke et al. 2005) based on 3 study sites in the south of the UK, assessed in a single calendar year, to emphasize the similarity of the findings of all 4 studies.

\section{DISCUSSION}

In this study we tested the specific a priori hypothesis that the presence of the dominant intestinal nematode of wood mice, $H$. polygyrus, predisposes wood mice to infection with other helminths. We predicted that the prevalence of other helminth species would be higher in the presence of $H$. polygyrus, and that the 

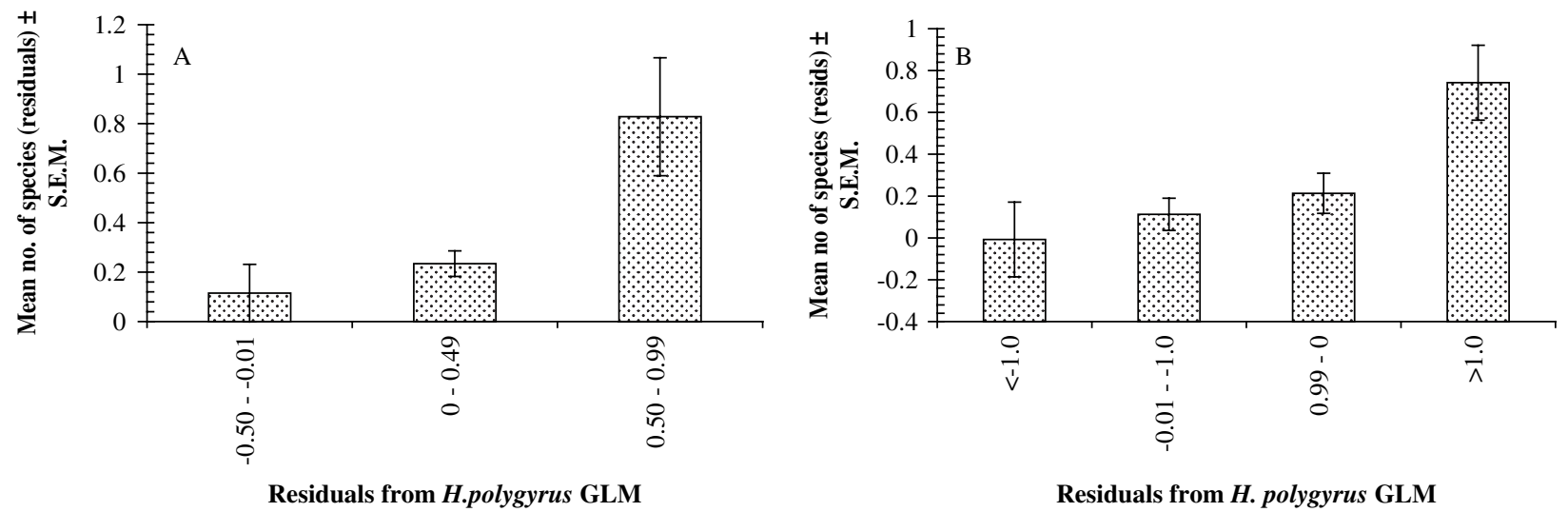

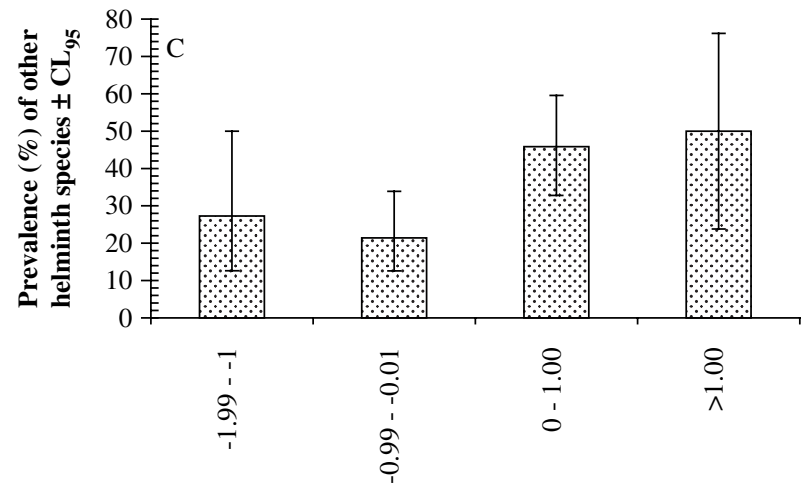

Residuals from $H$. polygyrus GLM

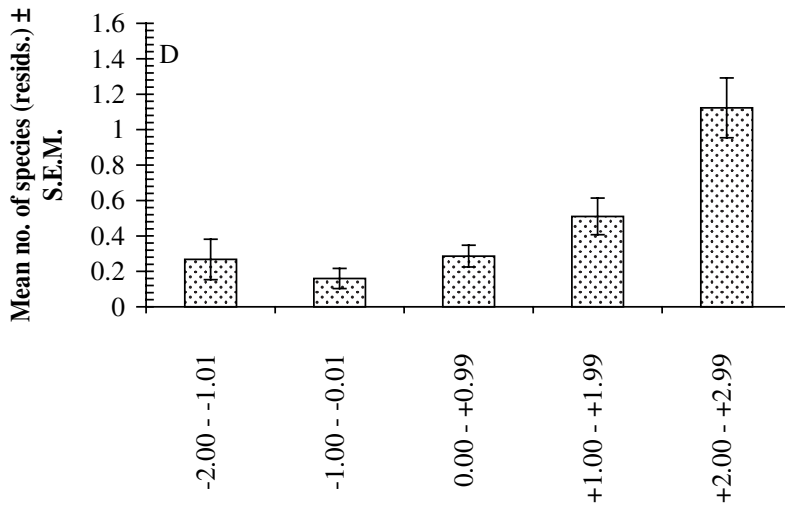

Residuals from $H$. polygyrus GLM

Fig. 4. Relationship between the intensity of Heligmosomoides polygyrus infection and number or prevalence of other species of helminths harboured by wood mice expressed in the form of histograms, with the residuals of the H. polygyrus GLMs in class ranges as shown on the abscissa. (A) Portuguese dataset (no. of mice in columns from left to right $=21$, 148 and 9). (B) Egham dataset (no. of mice in columns from left to right =14, 73, 56, and 14). (C) Malham dataset (prevalence of other helminth species; no. of mice in columns from left to right=22, 84, 96 and 14). (D) For comparison with the above, data reproduced from Behnke et al. (2005) showing the same relationship in the dataset of Abu-Madi et al. $(1998,2000)$ collected from wood mice in 3 different habitats in the south of the UK (no. of mice in columns from left to right $=16,59,76,22$ and 6).

species richness of other helminths would also increase with increasing worm burdens of $H$. polygyrus. These two predictions were based on the findings of Behnke et al. (2005) from 3 ecologically contrasting sites in the UK. Here we tested the robustness of this finding in 3 additional datasets unrelated to one another. Since the current analysis was focused on just 2 predictions, each analysed by a well-defined statistical approach, it was free of the confounding problems of multiple comparisons (including Type I errors) that invalidate many other studies of interactions between species. It is clearly evident from our results that our predictions were both borne out. Both relationships (the presence/ absence of other helminth species and the species richness of other helminths) held up in 2 datasets, and there was strong support for a similar relationship in the third dataset (Malham) where overall species richness was poor in comparison to the first 2 study sites. The data were collected in geographically different extremes of Europe and in ecologically quite distinct habitats with different combinations of helminths. On the basis of these results we are confident in concluding that indeed $H$. polygyrus has an effect on other co-infecting helminths in wood mice, and therefore that quantitative interactions between helminths infecting wild wood mice exist and contribute to infracommunity structure at the individual host level, and to component community structure at the population level.

Perhaps counter-intuitively, the current analysis does not indicate that the mice that are most heavily infected with $H$. polygyrus in any population are those most likely to carry also a wide range of other helminths. Rather, our data show that mice more heavily infected with $H$. polygyrus for their own particular subset (i.e. relative to the average burden for a particular year, site, season, age and sex) are the individuals that are most predisposed to being concurrently infected with other helminth species, and the more heavily they are infected for their subset, the more likely they are to carry a greater range of other species than their uninfected or less heavily infected conspecifics.

Whilst correlational analyses such as the current work can never prove cause and effect, there is 
already a substantial body of information in the experimental field indicating that the very closely related congener $H$. bakeri has a marked immunodepressive effect on its host, particularly at the local intestinal level, and that as a consequence other helminths reside longer than they normally would in concurrently infected mice (reviewed by Behnke, 1987). Our data are consistent with the idea that $H$. polygyrus in wild populations of wood mice behaves similarly, not only facilitating its own survival but equally providing an opportunity for other species of helminths to exploit the host's weakened intestinal defences to benefit their own survival and reproductive effort. We are unaware of any experimental assessments of the immunocompetence of wild wood mice carrying heavy burdens of $H$. polygyrus, but Jackson et al. (manuscript in preparation) have recently reported that the abundance of $H$. polygyrus in wild wood mice correlates negatively with innate immune responsiveness, implying that this parasite like $H$. bakeri does have immunomodulatory properties.

In recent years, the question of polyparasitism has attracted considerable attention (Graham, 2002; Lello et al. 2004; Graham et al. 2007), although in reality the subject has a long history of experimental investigation under laboratory conditions (Christensen et al. 1987; Behnke et al. 2001). The underlying mechanisms that lead to multiplespecies infections have come under both theoretical (Dobson, 1985) and experimental scrutiny (reviewed by Behnke et al. 2001; Behnke, 2008), driven partly by the ideas that limited intrinsic resources leave hosts with life-history choices relating to their defences against infection, and hence resistance to some species of parasites may be traded off against susceptibility to others (Jolles et al. 2008). In part this may be mediated by the compartmentalization of the immune system into apparently mutually antagonistic Th1 and Th2 driven arms (the former of which is optimal in protection against intracellular organisms, the latter more appropriate for metazoan parasites such as helminths) with resultant consequences for the epidemiology of important human infections controlled by these two arms of the immune system e.g. exacerbation of malaria by concurrent helminth infections (Druilhe et al. 2005; Graham et al. 2007). Motivation for the study of polyparasitism is also driven by the urgency to understand the epidemiological consequence of immunodepression inducing HIV infection, and other emerging diseases, in the context of an array of already established pathogens and symbionts which the host may harbour simultaneously and/or be exposed to throughout life (Pedersen and Fenton, 2006). In the context of parasites of wildlife, a particular threat may be posed by introduced host species, which once established generally have impoverished helminth communities in foreign ecosystems because some of their parasites are unsuccessful in surviving in a novel environment (Vignon et al. 2009), but others may spread to indigenous hosts and farmed livestock with resultant consequences for the balance of parasite communities and their influence on host fitness and survival (Hudson et al. 1998; Gortázar et al. 2007). For these reasons models of coinfection, such as those provided by wild rodent systems, provide an important avenue for testing relevant hypotheses; in this case the consequences of a potentially immunodepression inducing intestinal helminth. Field studies involving intervention, for example by treatment to selectively remove H. polygyrus (Ferrari et al. 2004), are logically the next step in assessing the overall importance of this nematode in facilitating infection with other helminths in wood mice (Pedersen and Greives, 2008).

The history of studies of interactions between helminths in wild rodents is long (Elton et al. 1931; Kisielewska, 1970), but until now no relationship has been discovered that is robust enough to be repeatedly demonstrated in different host populations, and under different ecological circumstances. Our study is therefore the first to do so, and given the prevailing view that quantitative interactions between intestinal helminths play a minor if any role in structuring helminth communities (Haukisalmi and Henttonen, 1993 ; Poulin, 2001; Behnke et al. 2005), our results, together with those of Behnke et al. (2005), provide firm evidence that at the level of species richness, if not at the level of individual species, a highly predictable element of co-infections in wood mice has now been defined: infection with $H$. polygyrus has detectable consequences for the susceptibility of wood mice to other helminth species, particularly those associated with the intestine.

We thank the many undergraduate students who contributed to the fieldwork at Egham and Malham over the years, our colleagues Professor P.S. Craig, Professor G. Hide, Dr S. Heath and Professor D. Storey, and all SPVS personnel at the Quiaios Field Station (Portugal). We are grateful to Drs P. Harris and J. Jackson for their comments on earlier drafts of this manuscript.

\section{REFERENCES}

Abu-Madi, M. A., Behnke, J. M., Lewis, J. W. and Gilbert, F. S. (1998). Descriptive epidemiology of Heligmosomoides polygyrus in Apodemus sylvaticus from three contrasting habitats in south-east England. Fournal of Helminthology 72, 93-100.

Abu-Madi, M. A., Behnke, J. M., Lewis, J. W. and Gilbert, F. S. (2000). Seasonal and site specific variation in the component community structure of intestinal helminths in Apodemus sylvaticus from three contrasting habitats in south-east England. Fournal of Helminthology 74, 7-16.

Behnke, J. M. (1987). Evasion of immunity by nematode parasites causing chronic infections. Advances in Parasitology 26, 1-71. 
Behnke, J. M. (2008). Structure in parasite component communities in wild rodents. Predictability, stability, associations and interactions .... or pure randomness? Parasitology 135, 751-766.

Behnke, J. M., Bajer, A., Sinski, E. and Wakelin, D. (2001). Interactions involving intestinal nematodes of rodents : experimental and field studies. Parasitology 122, S39-S49.

Behnke, J. M., Barnard, C. J. and Wakelin, D. (1992). Understanding chronic nematode infections: evolutionary considerations, current hypotheses and the way forward. International Fournal for Parasitology 22, 861-907.

Behnke, J. M., Lewis, J. W., Mohd Zain, S. N. and Gilbert, F. S. (1999). Helminth infections in Apodemus sylvaticus in southern England: interactive effects of host age, sex and year on the prevalence and abundance of infections. Fournal of Helminthology 73, 31-44.

Behnke, J. M., Gilbert, F. S., Abu-Madi, M. A. and Lewis, J. W. (2005). Do the helminth parasites of wood mice interact? Fournal of Animal Ecology 74, 982-993.

Booth, M. and Bundy, D. A. P. (1992). Comparative prevalences of Ascaris lumbricoides, Trichuris trichiura, and hookworm infections and the prospects for control. Parasitology 105, 151-157.

Bottomley, C., Isham, V. and Basáñez, M.-G. (2005). Population biology of multispecies helminth infection: interspecific interactions and parasite distribution. Parasitology 131, 417-433.

Buck, A. A., Anderson, R. I. and MacRae, A. A. (1978a). Epidemiology of poly-parasitism. I. Occurrence, frequency and distribution of multiple infections in rural communities in Chad, Peru, Afghanistan and Zaire. Tropenmedizin und Parasitologie 29, 61-70.

Buck, A. A., Anderson, R. I. and MacRae, A. A. $(1978 b)$. Epidemiology of poly-parasitism. II. Types of combinations, relative frequency and associations of multiple infections. Tropenmedizin und Parasitologie 29, 137-144.

Christensen, N. O., Nansen, P., Fagbeni, B. O. and Monrad, J. (1987). Heterologous antagonistic interactions between helminths and between helminths and protozoans in concurrent experimental infection of mammalian hosts. Parasitology Research 73, 87-410.

Dobson, A. P. (1985). The population dynamics of competition between parasites. Parasitology 91, 317-347.

Druilhe, P., Tall, A. and Sokhna, C. (2005). Worms can worsen malaria: towards a new means to roll back malaria? Trends in Parasitology 21, 359-362.

Eira, C., Torres, J., Vingada, J. and Miquel, J. (2006). Ecological aspects influencing the helminth community of the wood mouse Apodemus sylvaticus in Dunas de Mira, Portugal. Acta Parasitologica 51, 300-308.

Elton, C., Ford, E. B., Baker, J. R. and Gardiner, A. D. (1931). The health and parasites of a wild mouse population. Proceedings of the Zoological Society of London 1931, 657-721.

Ferrari, N., Cattadori, I. M., Nespereira, J., Rizzoli, A. and Hudson, P. J. (2004). The role of host sex in parasite dynamics: field experiments on the yellow-necked mouse Apodemus flavicollis. Ecology Letters 7, 88-94.

Gortázar, C., Ferroglio, E., Höfle, U., Frölich, K. and Vicente, J. (2007). Diseases shared between wildlife and livestock: a European perspective. European Fournal of Wildlife Research 53, 241-256.

Graham, A. L. (2002). When T-helper cells don't help: immunopathology during concomitant infections. The Quarterly Review of Biology 77, 409-434.

Graham, A. L. (2008). Ecological rules governing helminth-microparasite coinfection. Proceedings of the National Academy of Sciences, USA $\mathbf{1 0 5}$, 566-570.

Graham, A. L., Cattadori, I. M., Lloyd-Smith, J. O., Ferrari, M. J. and Bjornstad, O. N. (2007).

Transmission consequences of coinfection: cytokines writ large? Trends in Parasitology 23, 284-291.

Gregory, R. D., Keymer, A. E. and Clarke, J. R. (1990). Genetics, sex and exposure: the ecology of Heligmosomoides polygyrus (Nematoda) in the wood mouse. Fournal of Animal Ecology 59, 363-378.

Haukisalmi, V. and Henttonen, H. (1993). Coexistence in helminths of the bank vole Clethrionomys glareolus. I. Patterns of co-occurrence. Fournal of Animal Ecology 62, 221-229.

Haukisalmi, V. and Henttonen, H. (1998). Analysing interspecific associations in parasites: alternative methods and effects of sampling heterogeneity. Oecologia 116, 565-574.

Holland, C. V., Asaolu, S. O., Crompton, D. W. T., Stoddart, R. C., MacDonald, R. and Torimiro, S. E. A. (1989). The epidemiology of Ascaris lumbricoides and other soil-transmitted helminths in primary school children from Ile-Ife, Nigeria. Parasitology 99, 275-285.

Hominick, W. M. and Aston, A. J. (1981). Association between Pelodera strongyloides (Nematoda: Rhabditidae) and wood mice, Apodemus sylvaticus. Parasitology 83, 67-75.

Howard, S. C., Donnelly, C. A. and Chan, M.-S. (2001). Methods for estimation of associations between multiple species parasite infections. Parasitology 122, 233-251.

Howard, S. C., Donnelly, C. A., Kabatereine, N. B., Ratard, R. C. and Brooker, S. (2002). Spatial and intensity-dependent variations in associations between multiple species helminth infections. Acta Tropica 83, 141-149.

Hudson, P. J., Dobson, A. P. and Newborn, D. (1998). Prevention of population cycles by parasite removal. Science 282, 2256-2258.

Janovy, J., Jr. (2002). Concurrent infections and the community ecology of helminth parasites. Fournal of Parasitology 88, 440-445.

Janovy, J. Jr., Clopton, R. E., Clopton, D. A., Snyder, S. D., Efting, A. and Krebs, L. (1995). Species density distributions as null models for ecologically significant interactions of parasite species in an assemblage. Ecological Modelling 77, 189-196.

Jolles, A. E., Ezenwa, V. O., Etienne, R. S., Turner, W. C. and Olff, H. (2008). Interactions between macroparasites and microparasites drive infection patterns in free-ranging African buffalo. Ecology 89, 2239-2250. 
Keusch, G. T. and Migasena, P. (1982). Biological implications of polyparasitism. Reviews of Infectious Diseases 4, 880-882.

Kisielewska, K. (1970). Ecological organization of intestinal helminth groupings in Clethrionomys glareolus (Schreb.) (Rodentia). V. Some questions concerning helminth groupings in the host individuals. Acta Parasitologica Polonica 17, 197-208.

Lello, J., Boag, B., Fenton, A., Stevenson, I. R. and Hudson, P. J. (2004). Competition and mutualism among the gut helminths of a mammalian host. Nature, London 428, 840-844.

Lotz, J. M. and Font, W. F. (1994). Excess positive associations of communities of intestinal helminths of bats: a refined null hypothesis and a test of the facilitation hypothesis. Fournal of Parasitology 80, 398-413.

Monroy, F. G. and Enriquez, F. J. (1992). Heligmosomoides polygyrus: a model for chronic gastrointestinal helminthiasis. Parasitology Today $\mathbf{8}$, 49-54.

Montgomery, S. S. J. and Montgomery, W. I. (1990). Structure, stability and species interactions in helminth communities of wood mice Apodemus sylvaticus. International Fournal for Parasitology 20, 225-242.

Pedersen, A. B. and Fenton, A. (2006). Emphasizing the ecology in parasite community ecology. Trends in Ecology and Evolution 22, 133-139.

Pedersen, A. B. and Greives, T. J. (2008). The interaction of parasites and resources causes crashes in wild mouse population. Fournal of Animal Ecology 77, 70-377.

Poulin, R. (2001). Interactions between species and the structure of helminth communities. Parasitology 122, S3-S11.

Rogan, M. T., Craig, P. S., Hide, G., Heath, S., Pickles, A. and Storey, D. M. (2007). The occurrence of the trematode Plagiorchis muris in the wood mouse Apodemus sylvaticus in North Yorshire, UK. Fournal of Helminthology 81, 57-62.

Rohlf, F. J. and Sokal, R. R. (1995). Statistical Tables. W. H. Freeman and Company, San Francisco, CA, USA.

Suttle, K. B., Thomsen, M. A. and Power, M. E. (2007). Species interactions reverse grassland response to changing climate. Science 315, 640-642.

Tchuem Tchuenté, L-A., Behnke, J. M., Gilbert, F. S., Southgate, V. R. and Vercruysse, J. (2003). Polyparasitism with Schistosoma haematobium and soil-transmitted helminth infections among school children in Loum, Cameroon. Tropical Medicine and International Health 8, 975-986.

Venables, W. N. and Ripley, B. D. (1997). Modern Applied Statistics with S-Plus. Springer, New York, USA.

Vignon, M., Sasal, P. and Galzin, R. (2009). Host introduction and parasites: a case study on the parasite community of the peacock grouper Cephalopholis argus (Serranidae) in the Hawaiian Islands. Parasitology Research 104, 775-782. 